\title{
A Miniaturized Industrial Plant for Educational Purpose in Industrial Control
}

\author{
Victor Santos Matos* Thiago Pereira das Chagas* \\ * Mechatronics Laboratory, Universidade Estadual de Santa Cruz, BA, \\ (e-mail: victorlico.hp@gmail.com,tpchagas@uesc.br).
}

\begin{abstract}
This work presents a miniaturized industrial plant built to portray a hydraulic and thermal system. The system was developed in a low-cost open-source platform for studies in the fields of automation, dynamic systems, and control. In order to test its capacity, different techniques of classic and modern control, estimation, modeling, and identification were applied. It should be noted that the work provides the ability to reproduction and continuous development of the plant, and also examples of educational applications, reducing the demand for laboratory equipment acquisition for teaching and research in Universities.

Resumo: Este trabalho apresenta uma planta industrial miniaturizada construida para retratar um sistema hidráulico e térmico. O sistema foi desenvolvido em uma plataforma de baixo custo de código aberto para estudos nas áreas de automação, sistemas dinâmicos e controle. Para testar sua capacidade, foram aplicadas diferentes técnicas de controle clássico e moderno, estimação, modelagem e identificação. Deve-se notar que o trabalho fornece a capacidade de reprodução e desenvolvimento contínuo da planta, e também exemplos de aplicações educacionais, reduzindo a demanda por aquisição de equipamentos de laboratório para o ensino e pesquisa nas Universidades.
\end{abstract}

Keywords: Education; process control; industrial plant; embedded systems; Arduino.

Palavras-chaves: Educação; controle de processos; planta industrial; sistemas embarcados; Arduino.

\section{INTRODUCTION}

The engineering formation demands experimental and practical character (da Rocha Brito and Ciampi, 2007), in special in control and automation. According to Coelho et al. (2001), experiments by simulation are not enough and technical equipment are necessary to supply the demand for experience and applicability of theoretical content. In addition, with technological advances and needs coming from industry 4.0, new forms of teaching are needed to encompass these advances (Lasi et al., 2014), principally in control systems.

Following this trend, some commercial products are already used to promote this practical experience, like QUBE-Servo $2^{1}$, Coupled Tanks ${ }^{1}$, QDrone ${ }^{1}$, QBot2 ${ }^{1}$, DC Motor Position Control System Using PID ${ }^{2}$, Boiler control Demonstration ${ }^{2}$ and Process Control Engineering Experimentation Plant $^{3}$. They cover areas like classic, optimal, adaptive, neural and others control/estimation/identification methodologies practiced in chemical process, robotics, electronics, etc. These have been used not only for teaching, but for researching purpose too (Koutroulis et al., 2001).

However this kind of equipment requires high investment for acquisition (Rodriguez-Andina et al., 2010) and demands time and bureaucracy to be bought by Universi-

\footnotetext{
1 https://www.quanser.com/products/

2 https://www.aticoexport.com/product/

3 http://www.usdidactic.com/teaching-lab-equipment/
}

ties. Because of that, there is a trend of study for lowcost options based on embedded systems (D'Ausilio, 2012; Hercog and Jezernik, 2005). This type of system is already consolidated in industrial segment and could be easily applied for composing laboratory equipment capable of representing this segment, providing considerable cost reduction as education platforms (Malinowski and $\mathrm{Yu}, 2011$ ).

As shown, low-cost educational prototypes have been developed for practical study in the fields of automation, dynamic systems analysis and control ( $\mathrm{Lu}$ et al., 2007; Alvarado et al., 2006; Irigoyen et al., 2013; Soriano et al., 2014), with special attention to tank process (Saco et al., 2002; Pasamontes et al., 2012; Hlava et al., 2005; Johansson, 2000). It is proposed here the development of a system that constitutes a miniaturized industrial plant of a heated pump-fed tank, with controllable variables such as inlet flow, fluid level and temperature. Making this with a lowcost prototyping platform that communicates in real time with a computer.

The plant is constituted by a PVC pipe tank fed by a DC electric pump, with an AC heater inside, monitored by flow, level and temperature sensors. In addition there are some circuits: amplifiers, filters and a dimmer. All connected to an Arduino board, communicating via serial with software like Scilab and Matlab®.

Some methods were proposed to the system as didactical activities, like: transfer function response identification, proportional-integral controller (PI), regulator and state 
observer, Kalman filter (FK) and model predictive control (MPC). Although the proposed tank has capacity of applications related to heating, this subsystem will not be addressed in this work. Only level-related applications will be exemplified.

This paper is organized as follows: Section 2 presents constructive and functional (hardware and software) aspects of the plant. Section 3 proposes and develops didactic activities like phenomenological modeling; identification; classic, modern and optimal control and estimation techniques. And the conclusions are presented in section 4 .

\section{MATERIALS AND METHODS}

In this section it is presented the description of the constructive aspects of the plant, including materials and a piping and instrumentation diagram (PI\&D), which could already be used as teaching activities.

\subsection{System description}

The assembled system, Figure 1, is a miniaturized industrial plant with nonlinear characteristics, which is associated to liquid level, pump inlet flow rate and fluid temperature. Figure (a) shows the overall appearance of the kit. Figure (b), (c) and (d) show the pressure sensor for level measurement, the flow sensor and the pump, respectively.

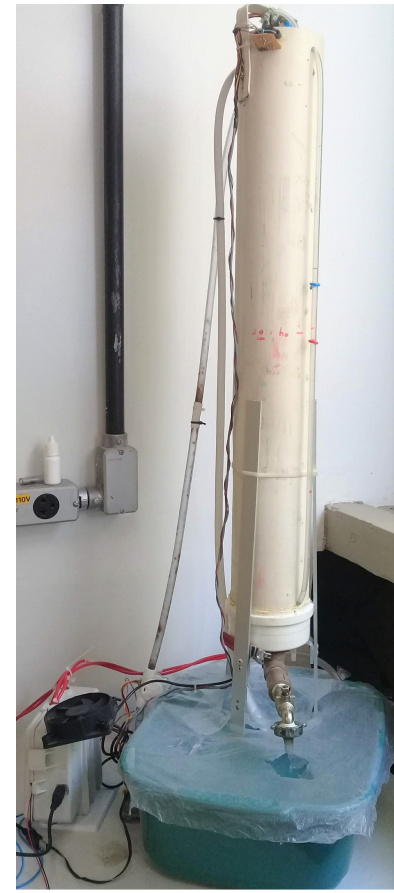

(a)

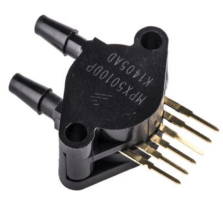

(b)


(d)
Figura 1. Constructive details of the kit (a) and instruments: (b) pressure sensor, (c) flow sensor, (d) pump.

The PI\&D, Figure 2, is formed by the main tank, another reservoir tank, a level metering system (LT), a centrifugal pump, an encoder flow meter (FE), a temperature sensor (TT), an electric heater, along with a digital signal acquisition system (FY and LY) and power amplification circuits (FC and TC). Finally, a mechanical valve to adjust the output flow. The elements are listed in Table 1 with their approximate local prices, which demonstrates the low cost feature of the system.

Tabela 1. List of components

\begin{tabular}{ccc}
\hline Code & Description & Price \\
\hline LT & MPX5010DP pressure sensor & $\mathrm{R} \$ 100.00$ \\
FE & YF-S402C flow sensor & $\mathrm{R} \$ 35.00$ \\
TT & DS18B20 temp. sensor & $\mathrm{R} \$ 20.00$ \\
FY, LY & Signal conditioner (in Arduino) & $\mathrm{R} \$ 50,00$ \\
FC & PI controller (in Arduino) & - \\
TC & 40A Dimmer circuit & $\mathrm{R} \$ 35.00$ \\
Heater & 5500W shower resistance & $\mathrm{R} \$ 10.00$ \\
Pump & Windshield washer pump 12V DC & $\mathrm{R} \$ 45.00$ \\
Valve & 1/2" water tap & $\mathrm{R} \$ 15.00$ \\
Power Supply & Output 12V DC 7A & $\mathrm{R} \$ 40.00$ \\
Main Tank & 100mm PVC pipe (and cap) & $\mathrm{R} \$ 35.00$ \\
Reservoir & 11L plastic container & $\mathrm{R} \$ 10.00$ \\
\hline
\end{tabular}

The (LT) is based in a differential pressure analog sensor with a tube immersed in the main tank as described in (Clifford, 2006). The fluid column in the tank applies a pressure at the pipe inlet proportional to the level $h(t)$. The proportional ratio is then manually calibrated according to the actual level.

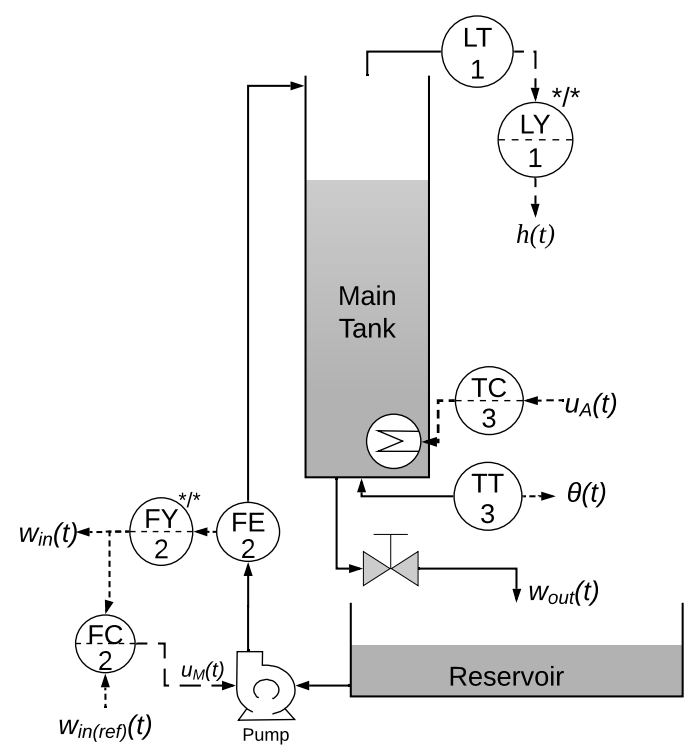

Figura 2. PI\&D of the plant.

\subsection{Acquisition System and Software}

The digital signal acquisition, control and communication system is formed by the educational open-source platform Arduino. Internally, there is a code that processes the serial communication $^{4}$ and defines the acquisition of data ${ }^{5}$ and the application of signals to actuators. Connected to it there are some auxiliary circuits - sensors filters ${ }^{6}$, actuators signal amplifier and an AC dimmer. This interface was ideally treated as a system without associated dynamics.

\footnotetext{
4 https://www.arduino.cc/reference/en/language/functions/ communication/serial/

5 https://maker.pro/arduino/tutorial/how-to-interface-arduinowith-flow-rate-sensor-to-measure-liquid

6 https://www.nxp.com/files-static/sensors/doc/datasheet/ $M P X 5010 . p d f$
} 
With this it is possible to use some software like Scilab (free and open-source) or Matlabß). Using the toolbox $W G$ Serial Xcos IO Block ${ }^{7}$ (XCOS environment) or Serial Port Interface $^{8}$ (Matlab code enviroment) for serial communication. This allows the practical implementation of signal analysis, systems and control by block diagram and code.

\section{DIDACTIC ACTIVITIES}

Some techniques were proposed with the purpose of validating the plant in educational application. The mathematical model of the system, the numerical identification and representation of its dynamics, the design and application of classic, modern and optimal controls.

\subsection{Level dynamics modeling}

Fluid level dynamics $\dot{h}(t)(1)$ was determined by mass $m$ conservation inside the tank and the relation between the inlet $w_{\text {in }}(t)$ and outlet $w_{\text {out }}(t)$ flows (Dorf and Bishop, 2009). Where $A_{1}$ is the area of the main tank base.

$$
\dot{h}(t)=\frac{w_{\text {in }}(t)-w_{\text {out }}(t)}{A_{1}}
$$

The outflow $w_{\text {out }}(t)$ is determined by the manual adjustment of the valve and responds to the laws of fluid dynamics. It can be obtained from the relation between the cross section area $A_{2}$ of the tap and the outlet velocity of the fluid by that area which, by Bernoulli's principle results in (2) (Dorf and Bishop, 2009). Where $g$ is the gravity acceleration.

$$
w_{\text {out }}(t)=A_{2} \sqrt{2 g} \sqrt{h(t)}
$$

Substituting (2) in (1) results in level dynamics model

$$
\dot{h}(t)=\frac{w_{i n}(t)-A_{2} \sqrt{2 g} \sqrt{h(t)}}{A_{1}} .
$$

The pump, in the form of a centrifugal pump, has its structures represented by (4) to (6), which respectively means armature circuit, rotor mechanics and hydraulics (Isermann and Münchhof, 2010).

$$
\begin{gathered}
\dot{I}_{b}(t)=\frac{-R_{b} I_{b}(t)-\Psi \omega(t)+U_{b}(t)}{L_{b}} \\
\dot{\omega}(t)=\frac{\Psi I_{b}(t)-M_{f 0}-\rho g h_{t h} \omega(t) w_{i n}(t)}{J_{B}} \\
\dot{w}_{i n}(t)=\frac{\left(h_{n n}-h_{r r}\right) w_{i n}^{2}(t)}{a_{f}}
\end{gathered}
$$

Where $L_{b}$ is the armature inductance, $R_{b}$ armature resistance, $I_{b}(t)$ armature current, $\Psi$ motor constant, $\omega(t)$ rotor angular velocity, $U_{b}(t)$ the voltage applied, $J_{B}$ pump's moment of inertia, $M_{f 0}$ dry friction torque, $\rho$ fluid density, $h_{t h}$ pump head coefficient, $a_{f}$ tube characteristics, $h_{n n}$ delivered head coefficient and $h_{r r}$ flow friction in tube (Isermann and Münchhof, 2010).

It is notable that a level controller is deficient in the control of the pump subsystem. So it is indicated the use of a

\footnotetext{
7 https://atoms.scilab.org/toolboxes/wgserialxcosio/

8 https://www.mathworks. com/help/instrument/

serial-port-interface.html
}

control loop for the pump, preferably a closed-loop control with integral action. It could increase the robustness of the system to parametric variations, like replacement or its physical degradation (Nise and da Silva, 2002). A simple Proportional-Integral controller (PI) was adopted to ensure a closer approximation of a standardized, approximately linear and simplified dynamic. And for the following applications (4) to (6) will be replaced by the closed-loop linear equations of the PI-controlled pump with $w_{\text {in(ref) }}(t)$ as input and $w_{i n}(t)$ as output. The controller design will be presented in Section 3.3.

Finally, we have as subsystem input the reference pump flow $w_{\text {in(ref) }}(t)$ and outputs the input flow $\omega_{i n}(t)$ and height $h(t)$.

\subsection{Identification}

Based on Lyapunov's $1^{\text {st }}$ method, it was applied, via $X C O S$ in Scilab platform, a constant pump flow reference value $w_{\text {in }(r e f)_{O}}$, which results in a steady state flow $w_{i n_{O}}$, and waits until the level reaches the steady state $h_{O}$. The triplet $\left(w_{i n(r e f)_{O}}, w_{i n_{O}}, h_{O}\right)$ is the operation point. With this data, it is possible to determine incremental linear models for the pump and tank level dynamics around an operating point, only valid for minor disturbances around it (Farid Golnaraghi, 2009), where $x_{1}(t)=h(t)-h_{O}$; $x_{2}(t)=w_{i n}(t)-w_{i n_{O}}$ and $u(t)=w_{\text {in(ref })}(t)-w_{\text {in }(\text { ref })_{O}}(t)$. The data was saved and applied to the System Identification Toolbox, configured in default mode, in Matlabß and a linear and operation point based model was obtained in continuous transfer function form. This procedure already uses the pump controlled by the proposed PI control, described in the next section.

In the operation point $h_{O}=30 \mathrm{~cm}$ and $w_{i n_{O}}=20 \mathrm{~cm}^{3} / \mathrm{s}$, a step $5 \mathrm{~cm}^{3} / \mathrm{s}$ was applied. The input and output data was entered in the toolbox, resulting in two best-match continuous-time transfer function models, one $1^{\text {st }}$ order for the tank dynamics (7) and another $2^{\text {nd }}$ order for the controlled pump (8). This last one were not chosen as a $3^{r d}$ order model as expected by (4) to (6) because the $2^{\text {nd }}$ order one represented well the data, so the model order was reduced for simplicity.

$$
\begin{aligned}
\frac{H(s)}{W_{\text {in }}(s)} & =\frac{0.01097}{s+0.002579} \\
\frac{W_{\text {in }}(s)}{W_{\text {in (ref) }}(s)} & =\frac{5.84}{s^{2}+1.616 s+5.84}
\end{aligned}
$$

The level and pump model chosen is a 3rd order linear continuous-time model which is represented in state space and discretized with sample time $T=0.3 s$ (same sample time of the real system) resulting in (9).

$$
\left\{\begin{aligned}
& \boldsymbol{x}_{k+1}= {\left[\begin{array}{ccc}
0.9992 & 0.0030 & 0.0004 \\
0 & 0.7847 & 0.2176 \\
0 & -1.2682 & 0.4331
\end{array}\right] \boldsymbol{x}_{k} } \\
&+\left[\begin{array}{l}
0.0003 \\
0.2157 \\
1.2706
\end{array}\right] u_{k} \\
& y_{k}=\left[\begin{array}{lll}
1 & 0 & 0
\end{array}\right] \boldsymbol{x}_{k}
\end{aligned}\right.
$$


Where $\boldsymbol{x}_{k}=\left[x_{1_{k}} x_{2_{k}} x_{3_{k}}\right]^{T}, x_{3}(t)=\dot{w}_{i n}(t)$.

\subsection{Control methods}

The system is able to support several control techniques and some of them are described in the following. Project and application are based on linear system level model around an operation point previously obtained (9). Control methods were chosen to exemplify different educational applications.

\section{Classic Control: PID}

The first experiment is a classic PI controller illustrating the possibility of applying a discrete-time controller through difference equation directly on Arduino. Control gains were initially tunned using Ziegler-Nichols method (Seborg et al., 2010) and further refined using experimental adjustment based on proportional and integral actions knowledge. The PI controller is then discretized resulting in $K_{p}=0.585$ and $K_{i}=2.04$. Remember that, besides the educational purpose, the PI controller as an inner loop promotes a more reliable dynamics to tank level identification and control. In Figure 3 it is shown the pump flow closedloop dynamics and reference. A practical observation is that the pump saturates outside the range 0 to $30 \mathrm{~cm}^{3} / \mathrm{s}$.

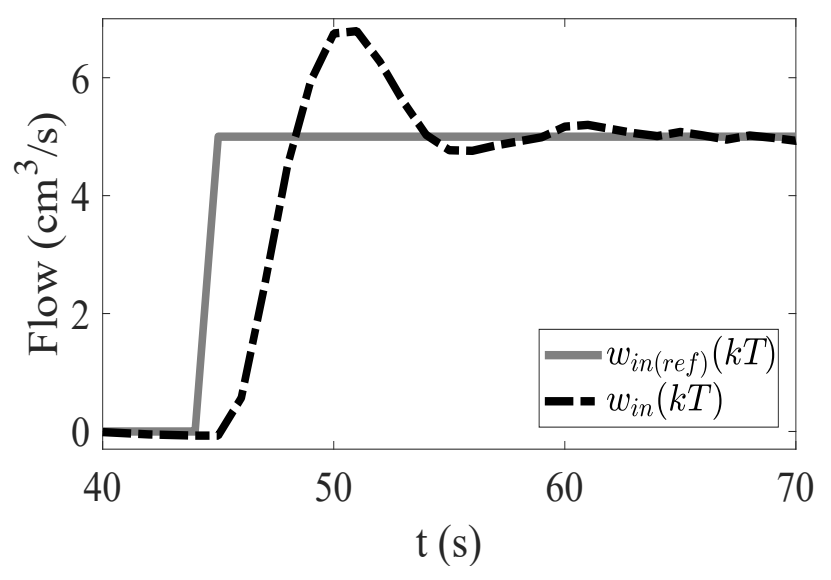

Figura 3. Controlled pump dynamics.

\section{Modern control: State observer and regulator}

State regulators are designed to stabilize the state space origin of a linear system and define transitory characteristics. Observers allow the estimation of unknown or unmeasured state of the system (Ogata, 1995).

If a system described like (10) satisfies the conditions of controllability and observability, an observer (11) and a regulator (12) can be designed by pole placement technique, based on the chosen performance specifications (Nise and da Silva, 2002). After that, (11) and (12) could be directly written in the Arduino's code and executed in the system.

$$
\begin{gathered}
\left\{\begin{array}{l}
\boldsymbol{x}_{k+1}=\boldsymbol{A} \boldsymbol{x}_{k}+\boldsymbol{B} u_{k} \\
y_{k}=\boldsymbol{C} \boldsymbol{x}_{k}
\end{array}\right. \\
\hat{\boldsymbol{x}}_{k+1}=(\boldsymbol{A}-\boldsymbol{L} \boldsymbol{C}) \hat{\boldsymbol{x}}_{k}+\boldsymbol{B} u_{k}+\boldsymbol{L} y_{k} \\
u_{k}=-\boldsymbol{K} \hat{\boldsymbol{x}}_{k}
\end{gathered}
$$

Where $\boldsymbol{x}_{k} \in \mathbb{R}^{3}$ is the state vector, $u_{k} \in \mathbb{R}^{1}$ input vector, $y_{k} \in \mathbb{R}^{1}$ is output vector, $\boldsymbol{A} \in \mathbb{R}^{3 \times 3}$ state matrix, $\boldsymbol{B} \in$
$\mathbb{R}^{3 \times 1}$ input matrix, $\boldsymbol{C} \in \mathbb{R}^{1 \times 3}$ output matrix, $\boldsymbol{K} \in \mathbb{R}^{1 \times 3}$ control gain matrix, $\boldsymbol{L} \in \mathbb{R}^{3 \times 1}$ observer gain matrix.

Practical specification were chosen to the design (seetling time $t_{s}=9 \mathrm{~s}$ and observer dynamics 5 times faster), resulting in $\boldsymbol{K}=\left[\begin{array}{lll}373.0155 & 5.4968 & 2.8666\end{array}\right]$ and $\boldsymbol{L}=$ $\left[\begin{array}{lll}1.7281 & 197.7781 & -56.0206\end{array}\right]^{T}$. A perturbation of $200 \mathrm{~cm}^{3}$ of water was direct applied to the main tank at $t_{d}$ instant.

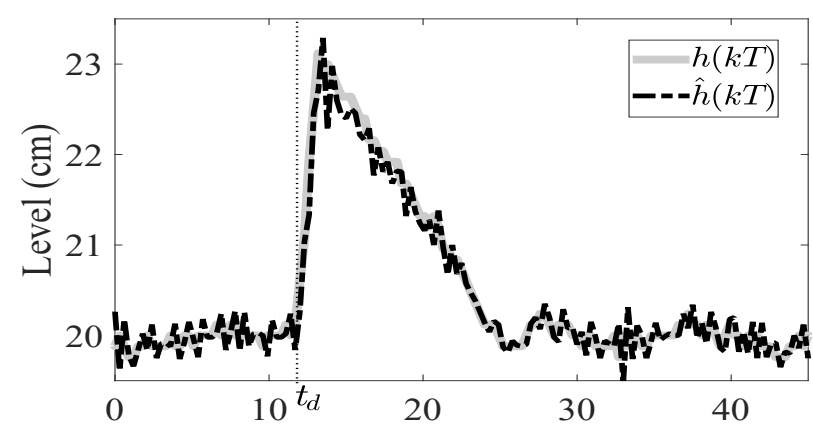

(a)

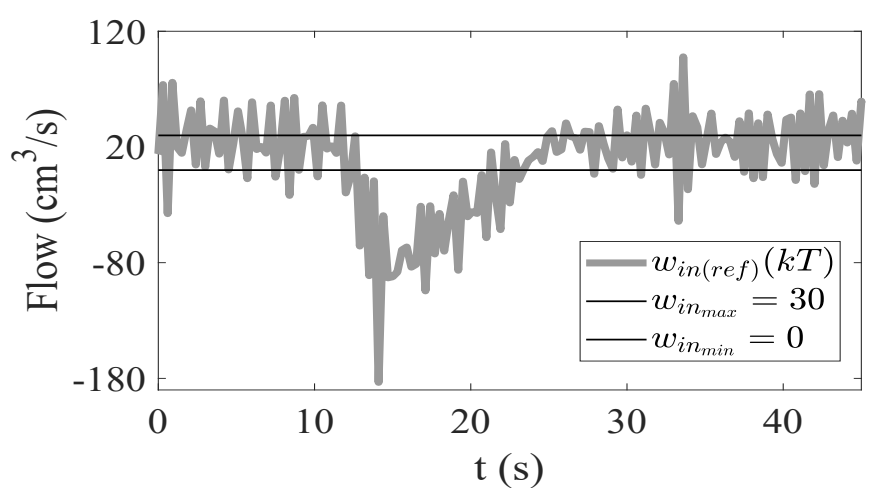

(b)

Figura 4. Classic observer and regulator dynamics for a $200 \mathrm{~cm}^{3}$ volume disturb: (a) level $h$, (b) reference flow $w_{\text {in }(r e f)}$.

As seen in Figure 4(a), the system was regulated, then the perturbation on system level increased it and the regulator actuated with output returning to reference of the linear system $\left(h_{o}\right)$. Oscillatory behaviour was observed in the output and its amplitude could be reduced with better regulator and/or observer gains tuning.

By Figure $4(\mathrm{~b})$, once $w_{i n_{k}} \in\left[w_{i n_{\text {min }}}, w_{i n_{\max }}\right]=[0,30]$ $\mathrm{cm}^{3} / \mathrm{s}$ because of the pump limits, it could be inferred that $u_{k}$ is not achieved in practice. This interfered in control in control performance, as seen by the higher settling time.

In Figure 4(a) it is possible to see the observer worked relatively well, it approximated $\hat{h}_{k}$ to $h_{k}$. The other states had been estimated and used in the control law, but were not shown graphically, due to the inability to measure all of them.

\section{Optimal control: Kalman filter and MPC}

This example is used to show more capabilities of the proposed didatical plant. In this case a Kalman filter and a MPC are applied using a Matlabß code and Arduino is used for communication between computer and plant (note 
that the pump PI controller still runs in Arduino). This methodology allows implementation of different modern control and estimation methods easily to the proposed plant and also using free and open source software like Scilab.

The MPC is a technique that uses the model of the plant to predict its future behavior and, with an optimization problem, the optimal input sequence is determined, here, to minimize the error between the reference $r_{k}$ and state variable $x_{1_{k}}$. Through the idea of receding horizon, the control sequence $u_{k}$ is updated at every sampling moment and constraints can be informed to achieve better performance (Rossiter, 2003).

A linear MPC algorithm with integral action was applied to the system (9) represented by (10), that was rewritten in the form (13) as described by Ruscio (2013). This new system (13) was associated to the performance index (14) and constraints (15). (13-15) is solved rewriting them as a Quadratic Programming (QP) form.

$$
\begin{aligned}
& \left\{\begin{array}{l}
\overbrace{\left[\begin{array}{c}
\Delta \boldsymbol{x}_{k+1} \\
y_{k}
\end{array}\right]}^{\tilde{\boldsymbol{x}}_{k+1}}=\overbrace{\left[\begin{array}{cc}
\boldsymbol{A} & \mathbf{0} \\
\boldsymbol{C} & \boldsymbol{I}
\end{array}\right]}^{\tilde{\boldsymbol{A}}} \overbrace{\left[\begin{array}{c}
\Delta \boldsymbol{x}_{k} \\
y_{k-1}
\end{array}\right]}^{\tilde{\boldsymbol{x}}_{k}}+\overbrace{\left[\begin{array}{c}
\boldsymbol{C} \\
\mathbf{0}
\end{array}\right]}^{\tilde{\boldsymbol{B}}} \Delta u_{k} \\
y_{k}=\overbrace{\left[\begin{array}{ll}
\boldsymbol{C} & \boldsymbol{I}
\end{array}\right]}^{\tilde{\boldsymbol{C}}} \overbrace{\left[\begin{array}{c}
\Delta \boldsymbol{x}_{k} \\
\boldsymbol{x}_{k-1}
\end{array}\right]}^{\tilde{\boldsymbol{x}_{k}}}
\end{array}\right. \\
& J_{k}=\frac{1}{2} \sum_{i=1}^{L_{y}}\left[\left(y_{k+1}-\boldsymbol{r}_{k+1}\right)^{T} \boldsymbol{Q}^{m p c}\left(y_{k+1}-\boldsymbol{r}_{k+1}\right)\right. \\
& \left.\left.+\sum_{i=1}^{L_{y}} \Delta u_{k+i-1}^{T} \boldsymbol{R}^{m p c} \Delta u_{k+i-1}\right)\right] \\
& \mathcal{A} \Delta u_{k \mid L_{u}} \leq \boldsymbol{b}_{k}
\end{aligned}
$$

Where $\Delta u_{k}$ is the control increment, $\boldsymbol{Q}^{m p c}$ and $\boldsymbol{R}^{m p c}$ are weights, $\mathcal{A}$ is a matrix with ones and zeros and $\boldsymbol{b}_{k}$ incorporates the limits $\Delta u_{\min }, \Delta u_{\max }, u_{\min }$ and $u_{\max }$ (Ruscio, 2013).

Solving QP, an updated vector $\Delta u$ with $L_{u}$ (control horizon) size is computed based on the predicted output vector with $L_{y}$ (predicted horizon) size and, normally, only the first one is applied $u_{k}=\Delta u_{k}^{*}+u_{k-1}$ where ${ }^{*}$ means optimal. All this happening at every sampling moment.

A linear Kalman Filter (FK) was also applied. An optimal observer capable to estimate the system state based on its model and white noise corrupted measurements (Grewal and Andrews, 2001).

First it is predicted the pre-state $\hat{\boldsymbol{x}}_{k}^{-}$(16) and the error covariance $\boldsymbol{P}_{k}^{-}(17)$, then the Kalman gain $\boldsymbol{K}_{k}^{f k}$ (18). Corrections are made after, resulting in $\hat{\boldsymbol{x}}_{k}(19)$ and $\boldsymbol{P}_{k}$ (20). In practical situation, there are noises added to (10), in $\boldsymbol{x}_{k+1}$, the process noise $w_{k}$, and in $y_{k}$, the measurement noise $v_{k}, w_{k} \sim \mathcal{N}\left(0, Q^{f k}\right)$ and $v_{k} \sim \mathcal{N}\left(0, R^{f k}\right)$. Where $\boldsymbol{Q}^{f k}$ is the process noise covariance and $\boldsymbol{R}^{f k}$ the measurement noise covariance, both acting like adjustable weights for the estimation/filtering process (Welch et al., 1995).

$$
\hat{\boldsymbol{x}}_{k}^{-}=\boldsymbol{A} \hat{\boldsymbol{x}}_{k-1}^{-}+\boldsymbol{B} u_{k-1}
$$

$$
\begin{gathered}
\boldsymbol{P}_{k}^{-}=\boldsymbol{A} \boldsymbol{P}_{k-1} \boldsymbol{A}^{T}+\boldsymbol{Q}^{f k} \\
\boldsymbol{K}_{k}^{f k}=\boldsymbol{P}_{k} \boldsymbol{C}^{T}\left(\boldsymbol{C} \boldsymbol{P}_{k}^{-} \boldsymbol{C}^{T}+\boldsymbol{R}^{f k}\right)^{-1} \\
\hat{\boldsymbol{x}}_{k}=\hat{\boldsymbol{x}}_{k}^{-}+\boldsymbol{K}_{k}^{f k}\left(y_{k}-\boldsymbol{C} \hat{\boldsymbol{x}}_{k}^{-}\right) \\
\boldsymbol{P}_{k}=\left(\boldsymbol{I}-\boldsymbol{K}_{k}^{f k} \boldsymbol{C}\right) \boldsymbol{P}_{k}^{-}
\end{gathered}
$$

The controller was configured with: $L_{u}=10, L_{y}=15$, $\boldsymbol{Q}^{m p c}=100 \cdot \boldsymbol{I}^{\left(L_{y} x L_{y}\right)}, \boldsymbol{R}^{m p c}=\boldsymbol{I}^{\left(L_{u} x L_{u}\right)}, \Delta u_{\min , \max }=$ $20 / 4.6, u_{\min }=-20$ ans $u_{\max }=10$. And the FK: $\boldsymbol{Q}^{f k}=$ $10000 \cdot \boldsymbol{I}^{(3 x 3)}, \boldsymbol{R}^{f k}=10$. The reference $r=40 \mathrm{~cm}$.


(b)

Figura 5. MPC and Kalman Filter dynamics for $40 \mathrm{~cm}$ level reference: (a) level $h$, (b) reference flow $w_{\text {in (ref) }}$.

From the Figure 5(a) it can be seen that the MPC was able to take the system to the desired reference and keep stable after that and the FK was able to estimate $x_{1}(t)$. From the Figure 5(b) the control effort remained in the restriction as defined in the specified constraints.

The MPC application showed here can be considered more complex than others techniques. This may confirm the capacity of the plant for more than practical study, but to research purpose.

\section{CONCLUSION}

The construction of low-cost MIMO practical tank process was presented. Focusing in the hydraulic subsystem (SISO), didactic activities were proposed and applied. A PI\&D were used to represent the system. A phenomenological nonlinear and an identified linear models were obtained with the knowledge of practical restrictions of the system, such as pump saturation. A classical control 
method - PI, and modern control - state observer and regulator were implemented directly in Arduino. A optimal control - KF and MPC were implemented by a computer communicating via serial with the plant.

It was possible to use a low cost embedded system for the construction of an educational plant. This system allowed the direct implementation of estimation and control techniques in its interior, besides being able to act as an acquisition board for computer control application. Favouring several other applications and techniques, including the development of other similar educational equipment.

Results presented here were able to exemplify the capabilities of the low-cost platform proposed in control/modeling/identification/estimation areas for educational and research purposes.

Therefore, this work can be continued, adding more functionalities and implementing countless others techniques, like exploring the thermal subsystem, proving more educational and validation of research results.

\section{ACKNOWLEDGEMENT}

This work was supported by Universidade Estadual de Santa Cruz in the project "Kit didático para controle de nível, vazão e temperatura em tanques com líquidos: Parte II".

\section{REFERÊNCIAS}

Alvarado, I., Limon, D., Garcia-Gabin, W., Alamo, T., and Camacho, E. (2006). An educational plant based on the quadruple-tank process. IFAC Proceedings Volumes, $39(6), 82-87$.

Clifford, M. (2006). Water level monitoring. Freescale Semiconductor Application Note AN1950.

Coelho, A.A., Almeida, O.M., Santos, J.E., and Sumar, R.R. (2001). Experimentos práticos de controle adaptativo na graduação. In XXIX Congresso Brasileiro de Ensino de Engenharia, Porto Alegre, RS, Setembro.

da Rocha Brito, C. and Ciampi, M.M. (2007). Engineering formation for 21st century: A challenge for brazil. In 2007 37th Annual Frontiers In Education ConferenceGlobal Engineering: Knowledge Without Borders, Opportunities Without Passports, T1A-1. IEEE.

Dorf, R. and Bishop, R. (2009). Sistemas de controle modernos. LTC.

D'Ausilio, A. (2012). Arduino: A low-cost multipurpose lab equipment. Behavior research methods, 44(2), 305313.

Farid Golnaraghi, B.C.K. (2009). Automatic Control Systems. Wiley, 9th edition.

Grewal, M.S. and Andrews, A.P. (2001). Kalman filtering: theory and practice using MATLAB. Wiley-Interscience, 2 edition.

Hercog, D. and Jezernik, K. (2005). Rapid control prototyping using matlab/simulink and a dsp-based motor controller. International Journal of Engineering Education, 21(4), 596.

Hlava, J., Ŝlc, B., and TamáŜ, J. (2005). A laboratory scale plant with hybrid dynamics and remote access via internet for control engineering education. IFAC Proceedings Volumes, 38(1), 1-6.
Irigoyen, E., Larzabal, E., and Priego, R. (2013). Low-cost platforms used in control education: An educational case study. IFAC Proceedings Volumes, 46(17), 256-261.

Isermann, R. and Münchhof, M. (2010). Identification of dynamic systems: an introduction with applications - 1ed. Springer Science \& Business Media.

Johansson, K.H. (2000). The quadruple-tank process: A multivariable laboratory process with an adjustable zero. IEEE Transactions on control systems technology, $8(3), 456-465$.

Koutroulis, E., Kalaitzakis, K., and Voulgaris, N.C. (2001). Development of a microcontroller-based, photovoltaic maximum power point tracking control system. IEEE Transactions on power electronics, 16(1), 46-54.

Lasi, H., Fettke, P., Kemper, H.G., Feld, T., and Hoffmann, M. (2014). Industry 4.0. Business \& information systems engineering, 6(4), 239-242.

Lu, B., Wu, X., Figueroa, H., and Monti, A. (2007). A lowcost real-time hardware-in-the-loop testing approach of power electronics controls. IEEE Transactions on Industrial Electronics, 54(2), 919-931.

Malinowski, A. and Yu, H. (2011). Comparison of embedded system design for industrial applications. IEEE transactions on industrial informatics, 7(2), 244-254.

Nise, N.S. and da Silva, F.R. (2002). Engenharia de sistemas de controle, volume 3. LTC.

Ogata, K. (1995). Discrete-time control systems, volume 2. Prentice Hall Englewood Cliffs, NJ.

Pasamontes, M., Alvarez, J.D., Guzman, J.L., and Berenguel, M. (2012). Learning switching control: A tank level-control exercise. IEEE Transactions on Education, $55(2), 226-232$.

Rodriguez-Andina, J.J., Gomes, L., and Bogosyan, S. (2010). Current trends in industrial electronics education. IEEE Transactions on Industrial Electronics, 57(10), 3245-3252.

Rossiter, J.A. (2003). Model-based predictive control: a practical approach. CRC press.

Ruscio, D. (2013). Model predictive control with integral action: A simple mpc algorithm. Modeling, Identification and Control: A Norwegian Research Bulletin, 34, 119-129. doi:10.4173/mic.2013.3.2.

Saco, R., Pires, E., and Godfrid, C. (2002). Real time controlled laboratory plant for control education. In 32nd Annual Frontiers in Education, volume 1, T2DT2D. IEEE.

Seborg, D.E., Mellichamp, D.A., Edgar, T.F., and Doyle III, F.J. (2010). Process dynamics and control. John Wiley \& Sons.

Soriano, A., Marin, L., Valles, M., Valera, A., and Albertos, P. (2014). Low cost platform for automatic control education based on open hardware. IFAC Proceedings Volumes, 47(3), 9044-9050.

Welch, G., Bishop, G., et al. (1995). An introduction to the kalman filter. 